EESTI NSV TEADUSTE AKADEEMIA TOIMETISED. XVIH KÖDE

KEEMIA * GEOLOOGIA. 1969, Nr. 1

ИЗВЕСТИЯ АКАДЕМИИ НАУК ЭСТОНСКОЙ ССР. ТОМ ХVII

Химия - ГЕОЛогИя. 1969. № 1

Г. СТЕПАНОВА, С. ФАИНГОЛЬД

\title{
АЛКИЛИРОВАНИЕ БЕНЗОЛА Н-ОКТЕНАМИ С РАЗЛИЧНЫМ ПОЛОЖЕНИЕМ ДВОЙНОЙ СВЯЗИ
}

Реакция алкилирования бензола алкенами $\mathrm{C}_{8}-\mathrm{C}_{14}$ широко используется при синтезе поверхностно-активных веществ. При изучении этой реакции большинство авторов обращало основное внимание на достижение максимального выхода моноалкилбензолов и подавление реакций образования диалкилбензолов и полимеров. Изомерный состав образующихся моноалкилбензолов исследовался меньше. Многие исследователи считали, что место присоединения бензола к алкильной цепи обусловливается положением двойной связи в молекуле алкена. Поэтому при термическом крекинге твердых парафинов разрабатываются условия для максимального выхода $\alpha$-олефинов $[1,2]$. Для получения олефинового сырья хлорирование жидких парафннов с последующим дегидрохлорированием хлоралканов в алкены применяется редко из-за образования алкенов с внутренним положением двойной связи.

В послецнее время Институтом химии АН ЭССР совместно со Всесоюзным научно-исследовательским институтом жиров показано, что лучшими моющими свойствами обладают алкиларилсульфонаты, содержащие бензольное ядро у крайних атомов vглерода углеводородной цепи $\left[{ }^{3}\right]$. Поэтому представляло интерес выяснить влияние положения двойной связи в молекуле алкенов на изомерный состав моноалкилбензолов.

Исследования проводились на индивидуальных октенах. Бензол алкилировался октенами в присутствии раствора хлористого алюминия в нитробензоле. Катализатор применялся в виде раствора с целью устранения нежелательных побочных реакций [ [ $\left.{ }^{4}\right]$.

\section{Обзор литературы}

Исследования реакции алкнлирования бензола алкенами с различным положением двойной связи в молекуле в литературе освещены слабо. Некоторые косвенные данные можно получить на основании опытов алкилирования бензола алкенами-1.

Олсон [5] изучал изомерный состав фенилдодеканов, полученных при алкилироваиии бензола додеценом-1 в присутствии хлористого алюминия, фтористоводородной и серной кислот. Он показал, что смесь фенилдодеканов содержала все возможные изомеры. Наибольшее содержание фенилдодеканов с внутренним положением бензольного ядра в алкильной цепи наблюдалось при использовании фтористоводородной кислоты, нанменьшее -- при применении серной кислоты. Хлористый алюминий занимал в этом отношении промежуточное положение.

Интерес представляет сделанное Олсоном наблюдение относительно превращений отдельных изомеров под действием хлористого алюминия в присутствии избытка бензола: из 2-и 6-фенилдодеканов образуются все возможные изомеры фенилдодеканов. 
С. Файнгольд и Х. Вооре $\left[{ }^{6}\right]$ изучали влияние условий алкилирования (хлористый алюминий, раствор его в нитробензоле, соотношение алкен: бензол) и нашли, что изменением этих условий не удается резко изменить изомерный состав.

Изучая алкилирование бензола ноненом-1 в различных условиях синтеза, С. Файнгольд, M. Қорв и В. Тээдумяэ $\left[{ }^{7}\right]$ получйли такие же результаты, как и Олсон с додеценом-1. Кроме того, они показали, что изменение температуры алкилировашия от 5 до $60^{\circ} \mathrm{C}$ существенно не влияет на изомерный состав фенилалканов.

Азингер и Фелл $\left[{ }^{8}\right]$ исследовали дейстьие различных катализаторов на изомеризацию двойной связи в моноолефиновых углеводородах, а также алкилирование последними бензола. Они пришли к выводу, что в тех случаях, когда катализатор не изомеризует образовавшиеся фенилалканы, изомерный состаз конечных продуктов алкилирования обусловливается предварительной изомеризацией двойной связи алкенов.

K катализаторам, не изомеризующим двойную связь, Азингер относит хлористый алюминий. С этим нельзя согласиться, так как в соответствии с ионной интерпретацией изомеризации двойной связи кислоты Льюиса являются активными донорами протонов, образующими с олефинами ион карбония. Как известно, ионы карбония легко изомеризуютсл в другие изомеры.

Действительно, Т. Лесмент, изучая изомеризацию двойной связи моноалкенов, установила, что в присутствии хлористого алюминия, в зависимости от времени контакта алкенов с катализатором, из октена-1 образуются все возможные изомеры $\left[{ }^{9}\right]$.

Гейселер, Геррманн и Кюрцель $\left[{ }^{10}\right]$ рассматривают реакцию алкилирования бензола гептеном-1 в присутствии концентрированной серной кнслоты как два параллельно протекающих процесса - изомеризацию двойной связи гептенов и алкилирование бензола всеми образующимися изомерами. Располагая данными об относительных константах равнокесия реакций прямой и обратной изомеризации и об изомерном составе фенилалканов, они рассчитали соотношения констант скоростей реакций изомеризации и алкилирования. Пользуясь некоторыми допущениями и полагая, что скорость прямой изомеризации гептенов в 50 раз больше, чем обратной изомеризации, названные авторы пришли к выводу, что предварительная изомеризация гептенов протекает в семь раз быстрее, чем алкилирование ими бензола.

Так как процесс алкилирования сопровождается рядом реакций (изомеризация цвойной связи алкенов, многократное чередование реакций дезалкилирования и алкилирования, диспропорционирование алкильных групп и переалкилирование образующихся монофенилалканов), то суммарный состав конечных продуктов, по-видимому, зависит or условий опыта и относителіных скоростей протекания тех или иных реакций.

Некоторую ясность в эти вопросы может внести исследование зависимасти изөмерного состава фенилалканов от положения двойной связи в исходных алкенах.

\section{ЭКСПЕРИМЕНТАЛЬНАЯ ЧАСТЬ}

\section{Получение исходных октенов}

Для получения исходных алкенов с определенным положением двойной связи был проверен ряд методов, из которых наиболее удобным оказался способ частичного восстановления соответствующих алкинов, синтезированных из ацетиленида натрия и бромистых алкилов, в жидком. аммиаке.

В общем виде реакция протекает по схеме

$\mathrm{CH} \equiv \mathrm{CH}+\mathrm{Na} \rightarrow \mathrm{CH} \equiv \mathrm{CNa}$

$\mathrm{CH} \equiv \mathrm{CNa}+\mathrm{R}_{1} \mathrm{Br} \rightarrow \mathrm{CH} \equiv \mathrm{CR}_{1}+\mathrm{NaBr}$

$\mathrm{CH} \equiv \mathrm{CR}_{1}+\mathrm{NH}_{2} \mathrm{Na} \rightarrow \mathrm{NaC} \equiv \mathrm{CR}_{1}+\mathrm{NH}_{3}$

$\mathrm{NaC} \equiv \mathrm{CR}_{1}+\mathrm{R}_{2} \mathrm{Br} \rightarrow \mathrm{R}_{1} \mathrm{C} \equiv \mathrm{CR}_{2}+\mathrm{NaBr}$ 
Таблица 1

Свойства исходных октепов

\begin{tabular}{|c|c|c|c|c|c|c|c|c|c|}
\hline \multirow{3}{*}{ Показатели } & \multicolumn{2}{|c|}{ Октен-1 } & \multicolumn{3}{|c|}{$\begin{array}{c}\text { Октен-2 } \\
\text { (смесь цис- н транс- } \\
\text { нзомеров) }\end{array}$} & \multicolumn{2}{|c|}{ транс-Октен-3 } & \multicolumn{2}{|c|}{ транс-Октен-4 } \\
\hline & \multirow{2}{*}{$\begin{array}{c}\text { синтезн- } \\
\text { рованный }\end{array}$} & \multirow{2}{*}{$\mid \begin{array}{c}\text { Лит. } \\
\text { данные } \\
{\left[{ }^{11}\right]}\end{array}$} & \multirow{2}{*}{$\left|\begin{array}{c}\text { синте- } \\
\text { знро- } \\
\text { ванный }\end{array}\right|$} & \multicolumn{2}{|c|}{$\begin{array}{l}\text { Лит. данные } \\
\text { [i门] }\end{array}$} & \multirow{2}{*}{$\begin{array}{l}\text { сннтези: } \\
\text { рованный }\end{array}$} & \multirow{2}{*}{$\begin{array}{c}\text { Лит. } \\
\text { данные } \\
{[11]}\end{array}$} & \multirow{2}{*}{$\begin{array}{c}\text { сннте- } \\
\text { зиро- } \\
\text { ванный }\end{array}$} & \multirow{2}{*}{$\begin{array}{c}\text { Лит. } \\
\text { даннње } \\
{[11]}\end{array}$} \\
\hline & & & & utuc- & тринс- & & & & \\
\hline Температура. ${ }^{\circ} \mathrm{C}$ & $121,2-121,8$ & 121,28 & $125-126$ & 125.6 & 125,0 & $122-123$ & 123 & $121-123$ & 122,4 \\
\hline $\begin{array}{l}\text { Удельный вес } d_{4}{ }^{20} \\
\text { Показатель прелом. }\end{array}$ & 0,7151 & 0.7149 & 0.7211 & 0.7243 & 0,7199 & 0.7171 & 0,7156 & 0,7178 & 0.7144 \\
\hline ния $n_{D} 20$ & 1,4096 & 1.4087 & 1.4138 & 1,4150 & 1,4132 & 1,4118 & 1.4122 & 1.4128 & 1.4113 \\
\hline Бромное число & 139,0 & - & 135,0 & $T$ & - & 115 & - & 132,5 & - \\
\hline
\end{tabular}

Восстановление до алкенов осуществляется двумя способами: водородом в присутствии катализатора Линдлара $(\mathrm{Pd}$, осажденный на $\mathrm{CaCO}_{3}$ ) и натрием в жидком аммиаке. В первом случае получаются цисизомеры, во втором - транс-изомеры.

Данные о свойствах полученных и использованных в настоящей работе $н$-алкенов приведены в табл. 1 .

\section{Методика опытов}

Алкилирование проводилось в круглодонной колбе, снабженной мешалкой, термометром, обратным холодильником и капельной воронкой. В колбу, в которой находились катализатор и бензол, при постоянной температуре и перемешивании прибавляли необходимое количество олефина со скоростью 0,1 моль/ч, после чего перемешивание продолжалось в течение 1 часа. Температура алкилирования $35^{\circ}$. Катализатор - $10 \%$ ный раствор хлористого алюминия в нитробензоле. Количество катализатора - $15 \%$ хлористого алюминия на олефин, или 0,125 моль/моль. Таким образом, несмотря на различное соотношение алкен:бензол в отдельных опытах, реакционная смесь была всегда многократно разбавлена бензолом. Учитывая значительную длительность процесса, можно считать, что конечный изомерный состав смеси был равновесным.

Анализ продуктов реакции проводился на хроматографе УХ-1. Длина колонок - 6 м, жидкая фаза - полиэтиленгликоль 4000, твердая фаза-ИНЗ-600, температура колонки 180-190․ Газ-носитель - водород. Для определения выхода моноалкилбензолов обычно пользуются ректификацией. Более быстрым и в данном случае не уступающим реқтификации по полученным результатам является метод газо-жидкостной хроматографии с внутренним стандартом.

В качестве внутреннего стандарта был выбран нитробензол, потому что он является растворителем катализатора и количество его в ходе реакции остается неизменным. Так как нитробензол по химической природе отличается от фенилалканов, достоверность результатов была проверена на эталонных смесях. Данные газохроматографического анализа смесей приведены в табл. 2.

Из таблицы видно, что погрешность измерения в среднем составляет 7 -8\% при максимуме $16 \%$. Учитывая общую невысокую точность экспериментальных данных, эти результаты можно признать удовлетворительными. Точность их зависит, по-видимому, от температуры колонки и ее соответствия температуре кипения анализируемых фенилалканов. Так, при температуре $190^{\circ}$ точность анализа фенилоктанов выше, чем лри $170^{\circ}$. Об этом свидетельствуют также данные анализа смесей нитро- 
Результаты газохроматографического анализа искусственных смесей нитробензөла с фенилалканами

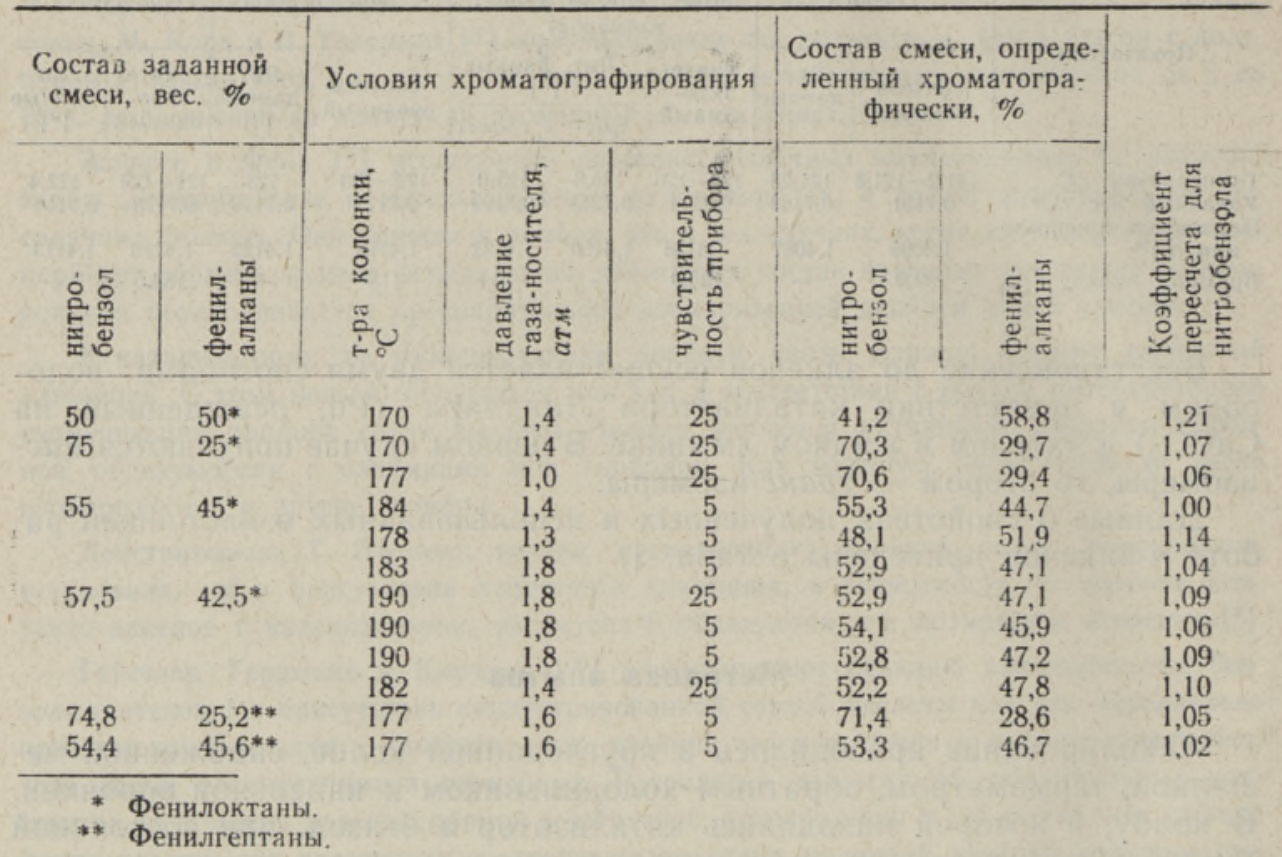

бензола с фенилгептанами. Изложенное показывает, что образовавшиеся в ходе опыта диалкилбензолы и полимеры с большим молекулярным весом и высокой температурой кипения при данных условиях хроматографирования практически не вытесняются.

\section{Изомерный состав фенилалканов, получаемых при алкилировании бензола октенами-1, -2, -3, -4}

Выходы и изомерный состав монофенилоктанов, полученных при алкилировании бензола октенами- $1,-2,-3,-4$ при молярном соотношении алкен: бензол $1: 2$, приведены в табл. 3.

Таблица 3

Выходы и изомерный состав монофенилоктанов, полученных при алкилировании бензола октенами

(температура $37^{\circ} \mathrm{C}$; катализатор - раствор $\mathrm{AlCl}_{3}$ в нитробензоле, 15 вес, \% $\mathrm{AlCl}_{3}$ на октен; соотношение октен : бензол $1: 2$ )

\begin{tabular}{|c|c|c|c|c|c|}
\hline \multirow{2}{*}{$\begin{array}{c}\text { Исходный } \\
\text { октен }\end{array}$} & \multirow{2}{*}{$\begin{array}{l}\text { Выход, \% } \\
\text { от теорети- } \\
\text { ческого }\end{array}$} & \multicolumn{3}{|c|}{ Изомерный состав фенилоктанов, \% } & \multirow{2}{*}{$\begin{array}{l}\text { Соотношение изо- } \\
\text { меров фенилокта- } \\
\text { нов 2-:3-: 4- }\end{array}$} \\
\hline & & $\begin{array}{l}\text { 2-фенил- } \\
\text { октан }\end{array}$ & $\begin{array}{l}\text { 3-фенил- } \\
\text { октан }\end{array}$ & $\begin{array}{c}\text { 4-фенил- } \\
\text { октан }\end{array}$ & \\
\hline Октен-1 & 65,6 & 44,1 & 30,8 & 25,1 & $1,8: 1,2: 1,0$ \\
\hline Октен-2 & 67,2 & 41,5 & 33,0 & 25.5 & $1,6: 1,3: 1,0$ \\
\hline Октен-3 & 62,4 & 42,5 & 31,7 & 25,8 & $1,6: 1,2: 1,0$ \\
\hline \multirow[t]{2}{*}{ Октен-4 } & $34,0^{*}$ & 40,2 & 32,8 & 27,0 & $1,5: 1,2: 1,0$ \\
\hline & $57,5^{*}$ & 40,1 & 31,6 & 28,9 & $1,4: 1,1: 1,0$ \\
\hline
\end{tabular}

* Алкилирование бензола транс-октеном-4 не проходило полностью, бромное числь алкилата составляло 6,0 ; выходы приведены на превращенный октен-4. 
Из данных таблицы можно сделать вывод, что изомерный состав фенилоктанов в условиях этих экспериментов не зависит от места положения двойной связи исходных октенов. Некоторые незначительные колебания обусловливаются точностью использованного метода анализа. Небольное отклонение наблюдается в опытах с октеном-4. Необходимо отметить, что алкилирование октеном-4 вообе идет труднее и по сравнению с другими октенами дает меньший выход фенилоктанов с бо́льшим содержанием 4-фенилоктана.

Результаты опытов по изучению влияния соотношения реагирующих компонентов на выходы и изомерный состав фенилоктанов приведены в табл. 4 .

Таблица 4

Выходы и изомерный состав монофенилоктанов, полученных при алкилировании бензола октенами-1 и -2 при различном соотношении реагентов

(температура $37^{\circ} \mathrm{C}$; катализатор - pacтвор $\mathrm{AlCl}_{3}$ в нитробензоле, 15 вес. \% $\mathrm{AlCl}_{3}$ на олефин)

\begin{tabular}{|c|c|c|c|c|c|c|}
\hline \multirow{2}{*}{$\begin{array}{l}\text { Исходный } \\
\text { октен }\end{array}$} & \multirow{2}{*}{$\begin{array}{l}\text { Молярное } \\
\text { соотноше- } \\
\text { ние октен : } \\
: \text { бензол }\end{array}$} & \multirow{2}{*}{$\begin{array}{l}\text { Выход, \% } \\
\text { от теоре- } \\
\text { тического }\end{array}$} & \multicolumn{3}{|c|}{$\begin{array}{c}\text { Изомерный состав фенил- } \\
\text { октанов, \% }\end{array}$} & \multirow{2}{*}{$\begin{array}{l}\text { Соотношение изо- } \\
\text { меров фенилокта- } \\
\text { нов 2-:3-: } 4 \text { - }\end{array}$} \\
\hline & & & $\begin{array}{l}\text { 2-фенил- } \\
\text { октан }\end{array}$ & $\begin{array}{l}\text { 3-фенил- } \\
\text { октан }\end{array}$ & $\begin{array}{l}\text { 4-фенил- } \\
\text { октан }\end{array}$ & \\
\hline Октен- & $1: 2$ & 65,6 & & 30,8 & 25,1 & $1,8: 1,2: 1,0$ \\
\hline То же & $1: 4$ & 85,4 & & 30,2 & 24 & $1,9: 1,2: 1,0$ \\
\hline Октен-2 & $1: 2$ & 67,2 & 41,5 & 33,0 & 25,5 & $1,6: 1,3: 1,0$ \\
\hline То же & $1: 4$ & 84,4 & 46,9 & 28,0 & 24,7 & $1,9: 1,1: 1,0$ \\
\hline$"$, & $1: 8$ & 83,6 & 46.9 & 29,8 & 23,3 & $2,0: 1,3: 1,0$ \\
\hline
\end{tabular}

В обзоре литературы указывалось, что изомерный состав фенилалканов зависит как от предварительной изомеризации двойной связи в алкенах, так и от изомеризации образующихся фенилалканов, происходящей под действием хлористого алюминия в присутствии бензола. Поэтому изомерный состав должен зависеть не только от места положения двойной связи, но и от соотношения бензола и октена.

Опыты показывают, что при изменении соотношения бензола и октена изменить соотношение изомеров в смеси фенилоктанов не удается.

Дополнительно были проведены опыты по алкилированию бензола гептеном-1 и гептеном-3 в одинаковых условиях (см. табл. 5).

Таблица 5

Выходы и изомерный состав фенилгептанов, полученных при алкилировании бензола изомерами гептена

(температура $37^{\circ} \mathrm{C}$; катализатор - раствор $\mathrm{AlCl}_{3}$ в нитробензоле, 15 вес. \% $\mathrm{AlCl}_{3}$ на олефин; молярное отношение гептен : бензол $1: 2$ )

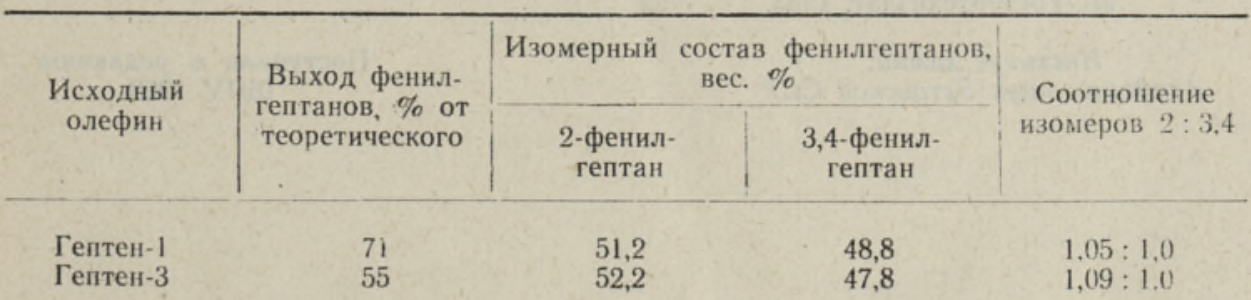

Эти опыты подтверждают, что изомерный состав фенилалканов не зависит от места положения двойной связи и что в реакциях алкилирования реакционная способность алкенов с внутренним расположением 
двойной связи меньше, чем у алкенов с концевым расположением этой связи.

Судя по литературным данным, основанным на термодинамических расчетах $\left[{ }^{10}\right]$, и результатам наших экспериментов, нельзя достоверно утверждать, что полученный изомерный состав фенилалканов является равновесным. Для этого необходимо провести дополнительные исследования по изомеризации фенилоктанов. Преобладание 2-фенилалканов в смеси изомеров, полученных при алкилировании бензола алкенами с внутренним положением двойной связи, можно объяснить как установлением равновесного состава, так и большей реакционной способностью алкенов с концевой двойной связью.

\section{Выводы}

1. Изомерный состав фенилалканов, образующихся при алкилировании бензола алкенами в присутствии раствора хлористого алюминия в нитробензоле, не зависит от расположения двойной связи в молекуле алкена.

2. Качественно установлено, что при алкилировании бензола индивидуальными алкенами реакционная способность алкенов зависит от их структуры. Алкены с концевой двойной связью реагируют легче, чем алкены с центральным положением двойной связи.

\section{Л ИТ Е Р А Т У Р А}

1. Лавровский К. П., Бродский А. М., Мусаев И. А., Санин П. И., Румянцев А. Н., Филато Е. Д., Исхакова Э. Х., Нефтехимия, 2, 487 (1962).

2. Панченков Г. М., Жоров Ю. М., Кузнецов О. И., Базияевич В. В., Нефтехимия, 5, 211 (1965).

3. Неволин Ф. В., Краль-Осикина Г. А., Бушуева Е. И., Файнгольд С. И., Т о м со н Р. М., Тр. ВННИЖ, вып. 26, 356 (1967)

4. Л ебедев Н. Н., ЖОХ, 9, 2461 (1957).

5. Ols o n A. C., Ind. Engng Chem., 52, 833 (1960).

6. Файнгольд С. И., Вооре Х. Ю., ЖПХ, 36, 2527 (1963).

7. Фай нгольд С., Корв М., Т ээдумя э В., Изв. АН ЭССР, Хим. Геол., 16, № 3. 217,222 (1967).

8. A s inge r F., Fell B., Erdöl u. Kohle, 19, 258 (1966).

9. Л ес мент Т., Изв. АН ЭССР, Хим. Геол., 16, № 4, 306 (1967).

10. Geiseler G., Herrmann P. u. Kürzel G., Chem. Ber., 98, 1695 (1967).

11. О боленцев Р. Д., Физические константы углеводородов жидких топлив и масед, Л., Гостоптехиздат, 1953.

Институт химии

Академии наук Эстонской ССР
Поступнла в редакцию I6/IV 1968 
G. STEPANOVA, S. FAINGOLD

\section{BENSEENI ALKUOLIMINE N-OKTEENIDEGA, MILLE KAKSIKSIDEME ASUKOHT ON ERINEV}

Uuriti benseeni alküülimist individuaalsete 1-, 2-, 3- ja 4-okteeniga alumiiniumkloriidi nitrobenseenlahuse juuresolekul.

Etteantud struktuuriga lähtealkeenid saadi vastavate oktiinide taandamisel.

Fenüüloktaanide isomeerne koostis ja saagis määrati gaasikromatograafiliselt, kus juures sisestandardiks oli nitrobenseen.

Tehti kindlaks, et fenüüloktaanide isomeerne koostis, mis tekib benseeni alküülimisel okteenidega alumiiniumkloriidi nitrobenseenlahuse juuresolekul, ei sõltu. kaksiksideme. asukohast'alkeeni molekulis.

Näidati, et alkeenid, mille kaksikside asub lōppasendis, reageerivad kergemini kui need, mille kaksikside asub süsivesiniku ahela keskel.

\section{G. STEPANOVA, S. FAINGOLD}

\section{ALKYLATION OF BENZENE WITH n-OCTENES WITH DIFFERENT POSITION OF THE DOUBLE BOND}

The alkylation of benzene with individual $n$-octene-1, $-2,-3$ or -4 in presence of nitro: benzene solution of aluminium chloride was investigated at $35^{\circ} \mathrm{C}$.

Individual octenes were prepared by reduction of corresponding octynes.

The isomer distribution of phenyloctanes and their yields were examined by gas liquid chromatographic analytical method. As internal standard, nitrobenzene was used, which was present in the reaction mixture.

It was established that isomer distribution of phenyloctanes is formed by alkylation of benzene under the experimental conditions independent from the position of the double bond of initial alkenes.

The alkenes with end double bond will probably react more easily than internal ones. 